\title{
EVALUATION OF SAFETY AND EFFICACY OF CAUDAL ADMINISTRATION OF BUPIVACAINE/ DEXMEDETOMIDINE VERSUS BUPIVACAINE/FENTANYL IN PEDIATRIC UNILATERAL HERNIA REPAIR \\ BY
}

Reem Sleem, M.Sc ${ }^{1}$, Ayman Al Baghdady, $\mathrm{PhD}^{2}$, Lamia El Wakeel, $\mathrm{PhD}^{1}$ and Abd El Aziz Abd Allah, $\mathrm{PhD}^{3}$

\section{FROM}

${ }^{1}$ Department of Clinical Pharmacy, Faculty of Pharmacy, Ain Shams University, Cairo, Egypt

${ }^{2}$ Department of Pediatric surgery, Faculty of Medicine, Ain Shams University, Cairo, Egypt

${ }^{3}$ Department of Anesthesia, Faculty of Medicine, Ain Shams University, Cairo, Egypt

\section{Abstract}

Background\& Aim: Effective postoperative analgesia is important from the patient's perspective and can also improve clinical outcomes. This study aimed to compare the effect of caudal bupivacaine plus fentanyl versus caudal bupivacaine plus dexmedetomidine on the recovery of anesthesia, postoperative analgesia required, hemodynamic stability\& neurological complications in pediatric unilateral hernia repair patients.

Patients \& Methods: 50 (ASA) grade I patients, aged 2-4 years with uncomplicated unilateral inguinal hernias treated as day cases were randomly allocated into either; Group I (BF), received Bupivacaine $0.25 \% 1 \mathrm{ml} \backslash \mathrm{kg}$, and fentanyl $1 \mu \mathrm{g} \backslash \mathrm{kg}$, or Group 2 (BD), received Bupivacaine $0.25 \% 1 \mathrm{ml} \backslash \mathrm{kg}$, and dexmedetomidine $1 \mu \mathrm{g} \backslash$ $\mathrm{kg}$.

Patients were evaluated in terms of pain and sedation using FLACC scale and Ramsay Sedation Scale, respectively. Haemodynamic stability and Neurological complications were assessed during the postoperative period and one day postoperatively. 


\section{Results:}

The median FLACC scale was significantly lower in BD group versus BF group. Neurological complications were significantly higher in BF group immediately postoperatively, while there was no significant difference between the 2 groups in day 1 postoperatively. There was no significant difference between the 2 groups with regards tohaemodynamic stability. The median Ramsay score was significantly lower in BF group versus BD group, while the mean respiratory rate was significantly lower in BD versus $\mathrm{BF}$, while there was no significant difference in the mean oxygen saturation between the 2 groups denoting better sedation in BD without affecting respiratory functions. The need for analgesia was not significantly different between the 2 groups.

Conclusion:The addition of dexmedetomidine to bupivacaine was accompanied by better pain relief and less sedation at 4 and 8 hours postoperative and less nausea, vomiting and dry mouth in the immediate postoperative period as compared to fentanyl in pediatric patients with unilateral uncomplicated inguinal hernia.

\section{Keywords:}

Dexmeditomedine, fentanyl, Pediatric, Inguinal hernia, Caudal anaesthesia.

\section{Introduction:}

In the last years, day surgery has become increasingly popular and now about $50 \%$ to $60 \%$ of pediatric surgery is performed as day case in most of the western countries like USA and UK (Ray and Basu, 2000). There are many potential advantages of pediatric day surgery. In addition to the generic advantages of shorter waiting times, fewer cancellations, lower costs, reduced risk of nosocomial infection, improved utilization of staff and hospital facilities, there are specific advantages allowing the child to receive better care suited to their needs (Meakin, 2001). Inguinal hernia repair is the most common surgical operation in childhood, and is considered the commonest day case surgery in pediatric population (Brandt,2008). The Key to success in pediatric day case surgery is proper patient selection, prevention of common postoperative complications and adequate pain management. Severe postoperative pain not only decreases the patients' functional capacity but also is associated with longer postoperative stay and higher incidence of unanticipated readmission. Pain may precipitate postoperative nausea and vomiting (PONV) which is another cause of unanticipated readmission. Hence, adequate pain management is mandatory in day case surgery and is receiving greater attention (Ray and Basu, 2000).

Gaitini etal, suggested that adding fentanyl $1 \mu \mathrm{g} / \mathrm{kg}$ to bupivacaine in the caudal epidural block in children did not influence plasma levels of epinepherine and norepinepherine, nor did it improve the analgesic intensity of the caudal block (Gaitini etal, 2000). Mason et al, suggested that dexmedetomidine has the advantage of preserving respiratory function and producing a sedation state identical to that of natural sleep (Mason et al., 2014). Addition of intrathecal dexmedetomidine to heavy 
bupivacaine $0.5 \%$ was more advantageous than fentanyl with special regard to its analgesic properties in diabetic surgical patients as reported by a recent trial (Tarbeeh and Mohamed, 2013). In another study by Singh et al, Bupivacaine-fentanyl mixture caused nausea and vomiting and itching as adverse effects with a significant frequency while bupivacane-clonidine mixture didn't cause any of these side effects(Singh J etal, 2012).

Based on the previous notion, we assumed that intrathecal dexmedetomidine adjuvant could be more advantageous than fentanyl adjuvant in pediatric surgical patients. Hence the current study was designed to compare the effect of intrathecal dexmedetomidine versus fentanyl added to bupivacine $0.25 \%$ on the recovery of anesthesia, postoperative analgesia required, hemodynamic stability\& neurological complications in pediatric surgical patients with inguinal hernia.

\section{Patients and methods}

This study was a randomized, parallel-group study conducted on 50 (ASA) grade I children aged 2-4 years, with uncomplicated unilateral inguinal hernia treated as day case surgery and submitted for hernia repair at Ain-Shams University Hospitals. The exclusion criteria were patient refusal, patients with major cardiac, respiratory, renal, hepatic disorders, history of hypersensitivity to drugs under investigation, patients $<2$ yrs or $>4$ yrs, bilateral or complicated inguinal hernias and any contraindication to regional anesthesia, namely; patients with coagulopathy, infection at puncture site, spine deformity or prior surgery, neuromuscular disorders. The local ethical committee Review Board at Faculty of Pharmacy, Ain Shams University, approved the study protocol, and the study was performed in accordance with the Declaration of Helsinki. All caregivers of enrolled children provided a written informed consent.

\subsection{Preoperative management}

The patients were screened for suitability by:1.History from parents about common cold, wheezy chest, cough and expectoration, fever and congenital anomalies.2. Physical examination: chest and heart auscultations, abdominal examination and examination of the back especially sacral area. 3. Investigations: complete blood picture, coagulation profile, and chest X-ray.

Subjects were randomized into one of two study groups (25 patients in each); the first group received caudal bupivacaine $0.25 \% 1 \mathrm{ml} / \mathrm{kg}$ plus fentanyl $1 \mu \mathrm{g} / \mathrm{kg}$, the second group recieved caudal bupivacaine $0.25 \% 1 \mathrm{ml} / \mathrm{kg}$ plus dexmedetomidine 1 $\mu \mathrm{g} / \mathrm{kg}$.

\subsection{Anesthetic management}

Patient monitoring was carried out via: pulse oximetry, 5-lead ECG, noninvasive blood pressure monitoring and capnography. Under strict aseptic technique, caudal block was performed in the lateral decubitus position using $22 \mathrm{G}$ spinal needle at the L3-L4 interspace after Inhalation induction using sevoflurane, followed by 
intravenous canulation using 22 or 24 cannula, after that laryngeal mask of appropriate size had been used for securing airway. Maintenance of anesthesia had been done by sevoflorane. Surgery was started usually after 15 minutes from caudal analgesia.

The studied solution was slowly injected over $10 \mathrm{~s}$ then the patient was turned supine. The study was carried out in a single-blind fashion. The time at which the injection was completed was considered the zero time of the study and all the times were recorded from this time. Intraoperative monitoring of heart rate, mean arterial blood pressure and oxygen saturation, respiratory rate as well as response to surgical stimulus (movement) were recorded $5 \mathrm{~min}$ from the zero time then every $15 \mathrm{~min}$. Any episodes of bradycardia, hypotension or desaturation were recorded. After completion of surgery, patients were transferred to the recovery room awake and were evaluated in terms of pain and sedation using FLACC scale and Ramsay Sedation Scale, respectively. Assessments were made immediately after the transfer and then after 15 minutes then after $30 \mathrm{~min}$ then every hour until they were ready to leave the hospital.

The hemodynamic parameters including heart rate, mean blood pressure and peripheral oxygen saturation were recorded in post anesthetic care unit (PACU) every $1 \mathrm{~h}$ till complete recovery from anesthesia. Rescue analgesic medication was done with the use of intramuscular diclofenac $1 \mathrm{mg} / \mathrm{kg}$ and the total analgesic requirements in the first $8 \mathrm{~h}$ after surgery were recorded. If the patient did not require analgesics for 24 hours, it was registered under the category of no necessity for analgesics. The time interval between the conduction of caudal block and time of receiving the first dose of analgesic was considered as duration of post-operative analgesia. Patients who experienced itching, nausea, vomiting and urine retention were recorded.

\subsection{Statistical analysis}

Statistical analysis was performed using SPSS software (statistical package for the social sciences, version 21, SPSS Inc., Chicago, IL, USA). Numeric values were expressed as mean \& standard deviation. Comparison of two mean values was done using the independent $t$ test or Mann Whitney test depending on the type of data. Fisher, chi square and freidman tests used also in statistical analysis. All p-values were two sided. $\mathrm{P}$ values $\leq 0.05$ were considered significant.

\section{Results:}

Out of a total of 105 children screened, 50 children fulfilled the inclusion criteria $\&$ were included in the study. There was no significant difference between both groups in age, gender, weight or hernia side. Moreover, no significant difference was found between both groups in all the measured preoperative clinical characteristics including; pulse, respiratory rate, oxygen saturation $(\mathrm{SaO} 2)$ and systolic (SBP) and diastolic blood pressure (DBP), (Table 1).

The mean pulse was significantly higher in the preoperative versus the intraoperative period and in the postoperative versus the preoperative period in both 
groups. The mean SBP was significantly higher in the preoperative versus the intraoperative period in the 2 groups. The mean DBP was significantly higher in the preoperative versus both the intraoperative and postoperative periods in both groups (Table 2).

The number of patients who developed nausea, vomiting and dry mouth in the immediate postoperative period was significantly higher in bupivacaine-fentanyl (BF) group versus bupivacaine-dexmedetomidine (BD) group. While there was no significant difference at day-1 postoperative between the 2 groups (Table 3 ).

There was no significant difference in the number of patients who developed urinary retention or itching neither in the immediate postoperative period nor at day-1 postoperative between the 2 groups (Table 3 ).

The FLACC scale, Ramsay score and respiratory rate were not significantly different between the 2 groups in neither the immediate postoperative period nor the 8 hrs postoperative period. While, the FLACC scale and respiratory rate were significantly lower in BD group versus BF group at the 2-hrs and 4-hrs postoperative periods, and the Ramsay score was significantly lower in the BF group versus BD group at both the 2-hrs and 4-hrs postoperative periods (Table 4).

The need for analgesia was not significantly different between the 2 groups in neither the immediate postoperative, 2-hrs, 4-hrs nor the 8-hrs postoperative period, and there was no significant difference between both groups in the total analgesic doses used postoperatively. 
Table 1:Patients' demographics and preoperative data

\begin{tabular}{|c|c|c|c|c|}
\hline Parameter & Group 1 & Group 2 & \multicolumn{2}{|c|}{$\mathrm{P}$ value } \\
\hline \multicolumn{5}{|l|}{ Gender; n $(\%)$} \\
\hline Male & $21(84 \%)$ & $21(84 \%)$ & \multirow{2}{*}{1.00} & \multirow{2}{*}{ \# } \\
\hline Female & $4(16 \%)$ & $4(16 \%)$ & & \\
\hline Age (yrs); mean \pm S.D & $2.9 \pm 0.7$ & $3.1 \pm 0.7$ & 0.379 & II \\
\hline Weight $(\mathrm{Kg}) ;$ mean \pm S.D & $14.1 \pm 2.5$ & $14.4 \pm 2.3$ & 0.701 & II \\
\hline \multicolumn{5}{|l|}{ Hernia side; n (\%) } \\
\hline Right & $12(48 \%)$ & $9(36 \%)$ & \multirow{2}{*}{0.39} & \multirow{2}{*}{$\S$} \\
\hline Left & $13(52 \%)$ & $16(64 \%)$ & & \\
\hline \multicolumn{5}{|l|}{ Preoperative Data: } \\
\hline Pulse (bpm); mean \pm S.D & $120.1 \pm 15.3$ & $116.5 \pm 17.1$ & 0.204 & $¥$ \\
\hline Systolic BP (mmHg); mean \pm S.D & $95.8 \pm 7.7$ & $95 \pm 6.9$ & 0.80 & $¥$ \\
\hline Diastolic BP $(\mathrm{mmHg})$; mean \pm S.D & $55.6 \pm 7.8$ & $53.2 \pm 7.1$ & 0.253 & $¥$ \\
\hline $\mathrm{SaO} 2 ;$ mean \pm S.D & $98.6 \pm 1.5$ & $97.8 \pm 1.6$ & 0.071 & $¥$ \\
\hline \multicolumn{5}{|c|}{ Abbreviations; yrs (years); $\mathrm{SaO}$ (oxygen saturation) } \\
\hline \multicolumn{5}{|c|}{$\begin{array}{l}\text { Statistical tests; \#Fisher’s exact; } \S \text { Chi Square; } ₫ \text { t test; } ¥ \text { ANOVA with repeated } \\
\text { measures.* p values }<0.05 \text { are considered significant. }\end{array}$} \\
\hline
\end{tabular}


Table 2: Clinical data evaluation at the preoperative, intraoperative \& postoperative periods between the 2 groups

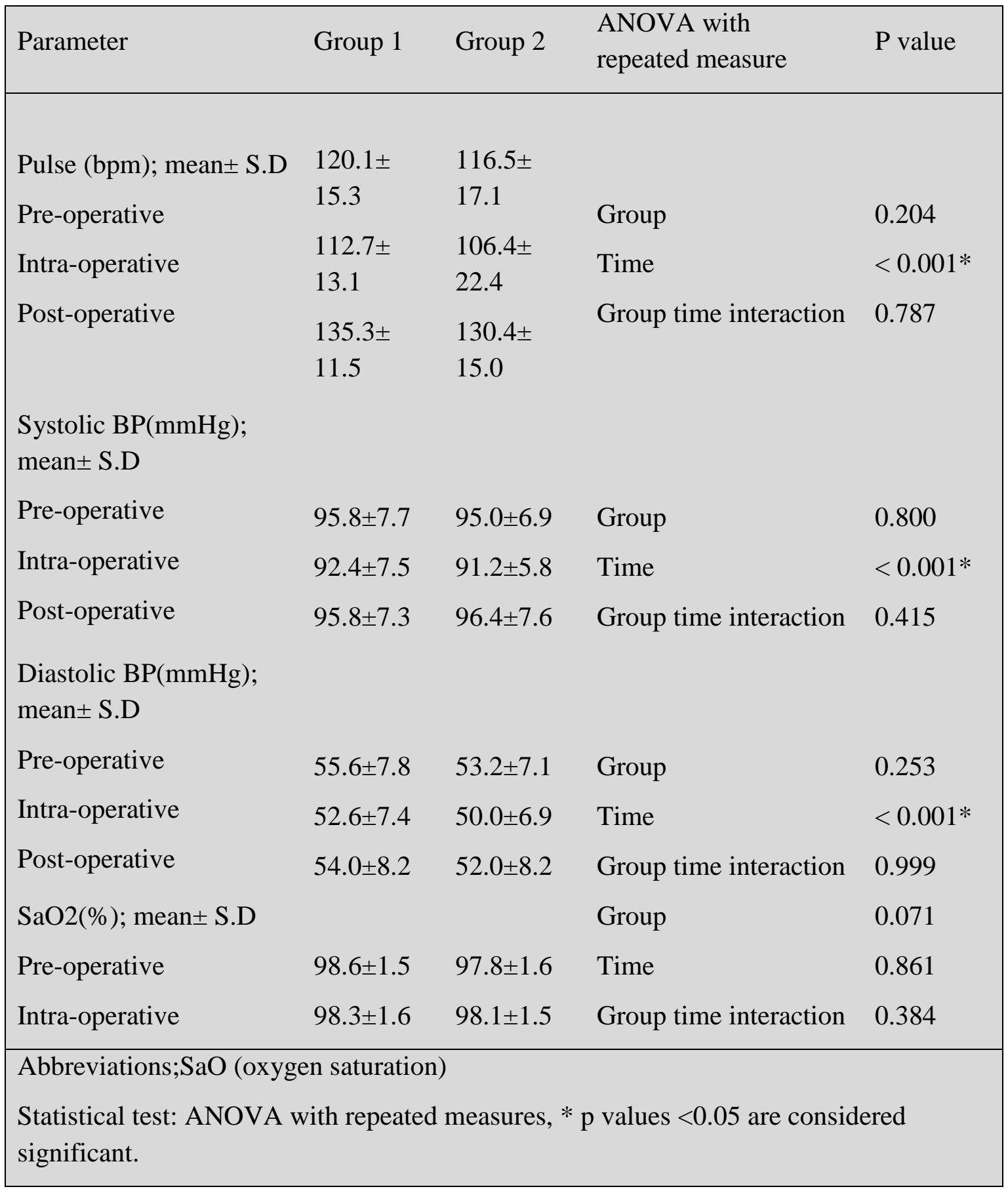


Table 3: Frequency of side effects in both groups in the immediate postoperative period \& one day postoperative

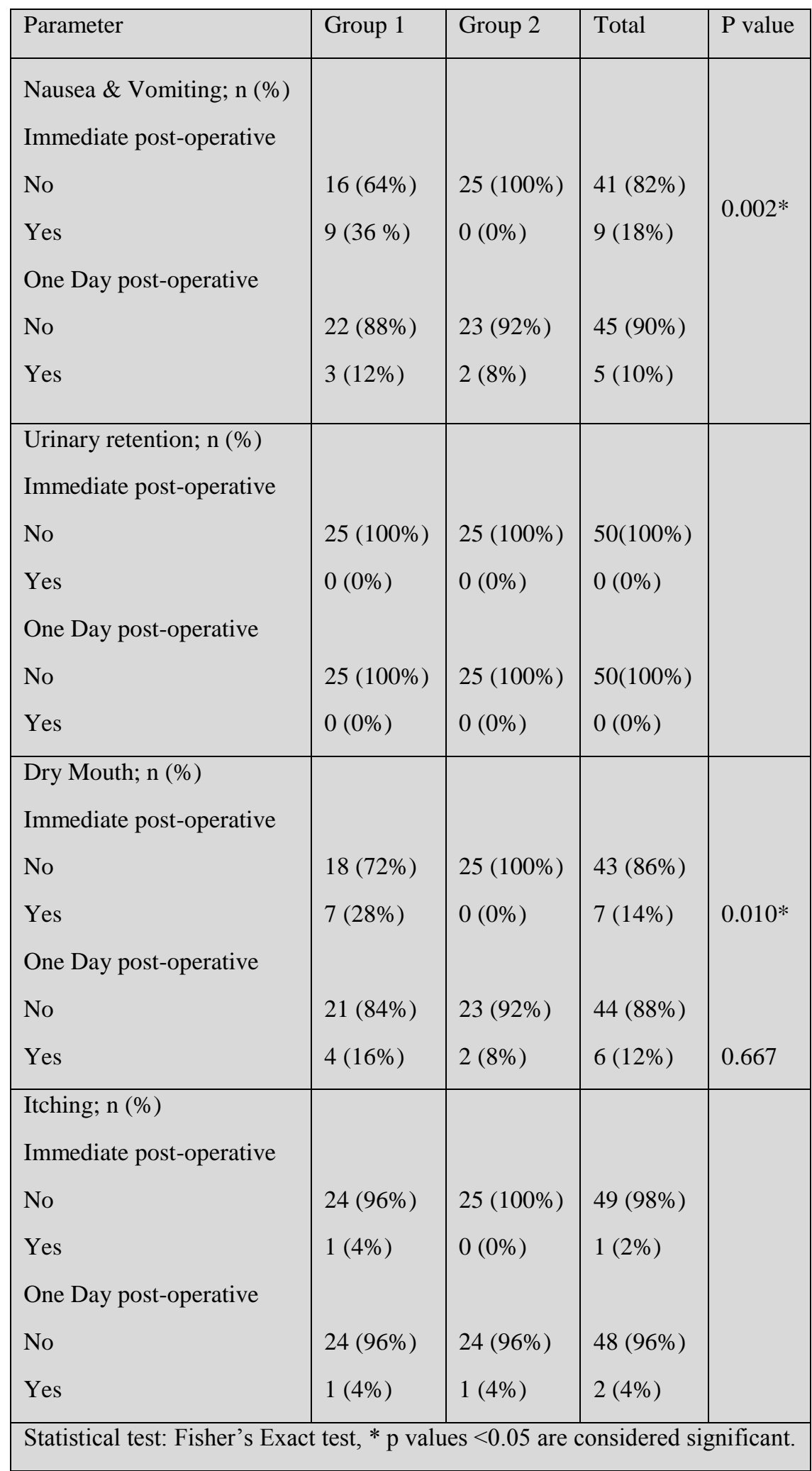


Table 4: Comparison of FLACC scale, RAMSAY scale, respiratory rate \& the need for analgesia between the 2 groups in the post-operative period

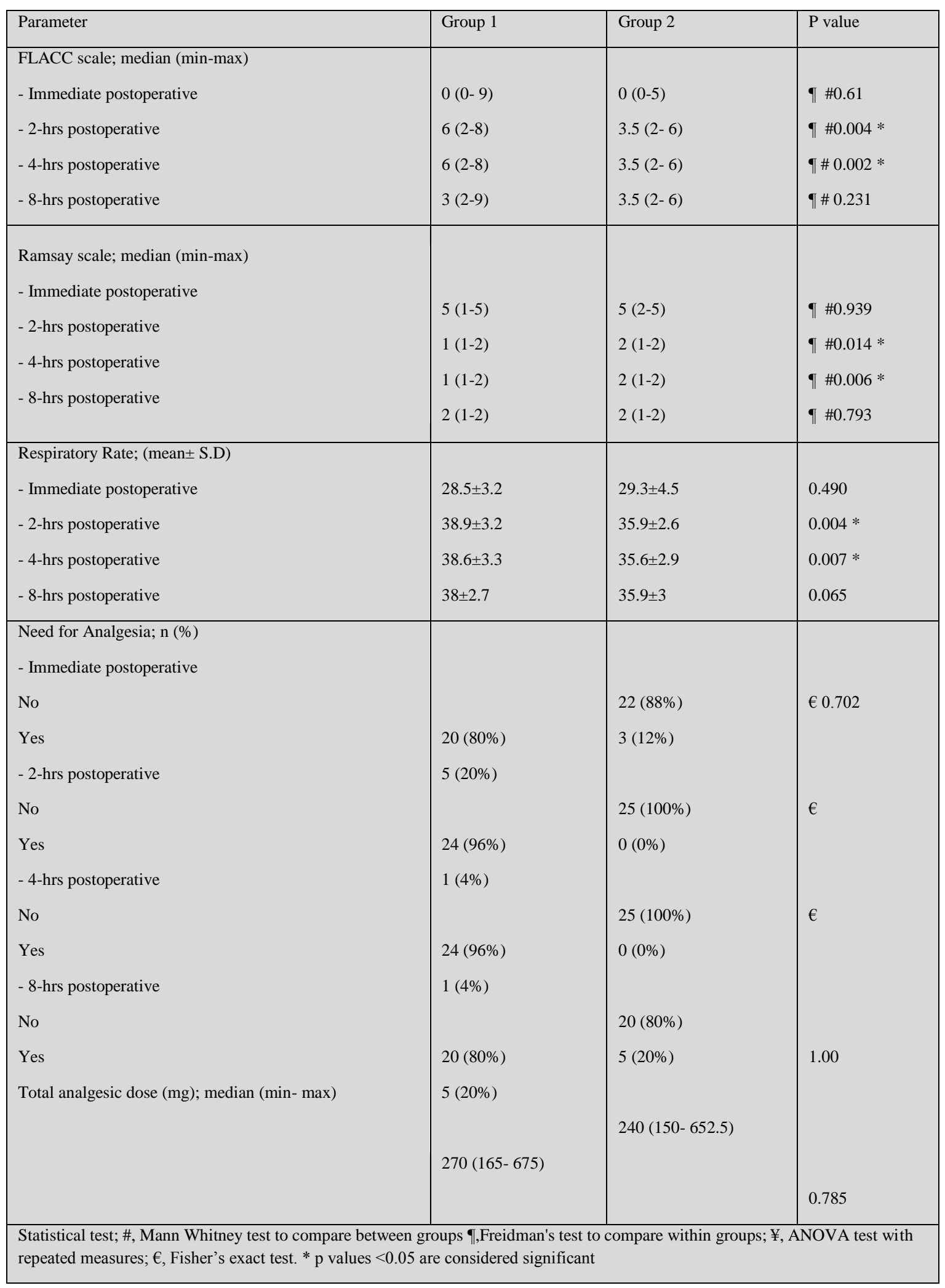




\section{Discussion:}

Results of the current study demonstrated that adding dexmedotomedine to Bupivacaine caudal anesthesia was accompanied by better pain relief and less sedation at 2 and 4 hours postoperative and less nausea, vomiting and dry mouth in the immediate postoperative period as compared to fentanyl addition to Bupivacainein pediatric patients with unilateral uncomplicated inguinal hernia.

In the current study, the median FLACC scale was significantly lower in the BD group versus the BF group at both the 2-hrs and 4-hrs postoperative periods denoting better control for pain and better analgesic effect with dexmedotomedineaddition to Bupivacaine. Similarly, Sharp et al, reported that dexmedetomidine was a useful sedative (Sharp et al, 2014). Moreover, Gupta R etal, reported that intrathecal dexmedetomidine was associated with prolonged motor and sensory block and hemodynamic stability as compared to fentanyl (Gupta $\mathbf{R}$ et al, 2011).

Results of the current study has shown that the Ramsay score was significantly lower in the fentanyl group versus the dexmedetomidine group at both the 2-hrs and 4hrs postoperative periods denoting better sedation in the dexmedetomidine group in which the patients were more cooperative, orientated and tranquil compared to patients in the fentanyl group who were more anxious and restless. Similarly, Saadawyi etal, reported that caudal dexmedetomedinewas found to be a promising adjunct to provide excellent analgesia without side effects over a 24 -h period and had the advantage of keeping the patients calm and sedated for a prolonged time (Saadawyi etal, 2009).

In the current study, the mean respiratory rate was significantly lower in the dexmedetomidine group than the fentanyl group at both the 2-hrs and 4-hrs postoperative periods but comparing the change over time between the 2 groups, there was no significant difference in the mean oxygen saturation from the preoperative versus the intraoperative periods in both groups. Moreover, there was no significant difference between the 2 groups at each time interval denoting that adding dexmedetomidine to caudal bupivacaine did not negatively affect respiratory functions. Similarly, El-Hennawy etal, reported a non-significant difference in the incidence of haemodynamic changes or respiratory depression when dexmedetomidine was added to caudal bupivacaine (El-Hennawy et al, 2009). Moreover, Sukhminder etal, reported that dexmedetomidine was a better adjuvant than clonidine in epidural anesthesia in terms of patient comfort, stable cardio-respiratory parameters, intra-operative and post-operative analgesia. Respiratory depression was not observed in any patient from either groups (Bajwa et al, 2011).

Regarding the postoperative need for analgesia in the current study, there was no significant difference between the 2 groups in neither the immediate postoperative period, 2-hrs, 4-hrs nor the 8-hrs postoperative period, neither was there a significant difference between both groups in the total analgesic doses used postoperatively. 
Similarly, Gupta et al, reported that dexmedetomidine was associated with prolonged motor and sensory block, hemodynamic stability, and reduced demand for rescue analgesics in 24 hours as compared to fentanyl but the difference was not significant (Gupta et al., 2011).

The current study showed that fentanyl was more significantly associated with nausea, vomiting and dry mouth as compared to dexmedetomidine. Similarly, Singh J etal, reported that bupivacaine-fentanyl mixture caused nausea and vomiting and itching as adverse effects in a significant rate while bupivacane-clonidine mixture didn't cause any of them (Singh $\mathbf{J}$ et al, 2012).

In conclusion, addition of dexmedetomidine to bupivacaine $0.25 \%$ was more advantageous than fentanyl with special regard to its sedative properties and neurological safety in day case pediatric surgical patients with unilateral uncomplicated inguinal hernia.

\section{REFERENCES:}

Brandt ML, 2008: Paediatric hernias. SurgClinNorthAm.; 88(1):27-43, vii-viii.

El-Hennawy A.M., Abd-Elwahab A.M., Abd-Elmaksoud A.M., et al, 2009: Addition of clonidine or dexmedetomidine to bupivacaine prolongs caudal analgesia in children. Oxford JournalsMedicineBJA;103(2): 268-274.

Gaitini L.A., MD, Somri M., MD, Vaida S. J., MD, 2000: Does the Addition of Fentanyl to Bupivacaine in Caudal Epidural Block Have an Effect on the Plasma Level of Catecholamines in Children. A \& A May; 90( 5): 1029-1033.

Gehan A. Tarbeeh, Ayman A. Mohamed, 2013 : Effects of intrathecal bupivacainefentanyl versus bupivacaine-dexmedetomidine in diabetic surgical patients. Egypt J anaesthesiol; 29(1):13-18.

G.H.Meakin, 2001: Muscle relaxants in paediatric day case surgery. Europe J Anaesthesiol; 18(23): 47-52.

Keira P. Mason, Dana $\quad$ P. Turner, Timothy $\quad$ T. Houle, Paulette J. Fontaine and Jerrold Lerman, 2014: Hemodynamic Response to Fluid Management in Children Undergoing Dexmedetomidine Sedation for MRI. Am J Roentgenol; 202(6): W574-W579.

Rajni Gupta, Reetu Verma, Jaishri Bogra, 2011: A Comparative study of intrathecal dexmedetomidine and fentanyl as adjuvants to Bupivacaine. J Anaesthesiol Clin Pharmacol.; 27(3): 339-343.

Ray Manjushree and Basu SM, 2000: Paediatric day case surgery. Ind J Anaesth; 44 (9): 5-8.

Saadawy.I, Boker A, Elshahawy MA, et al, 2009: Effect of dexmedetomidine on the characteristics of bupivacaine in a caudal block in pediatrics. Acta Anaesthesiol Scand.;53(2):251-6. 
Sharp BD, Wang X, Mendelowitz D, 2014: Dexmedetomidine decreases inhibitory but not excitatory neurotransmission to cardiac vagal neurons in the nucleus ambiguus. Brain Res;29(1574):1-5.

Singh J, Shah RS, Vaidya N,et al, 2012: Comparison of ketamine, fentanyl and clonidine as an adjuvant during bupivacaine caudal anaesthesia in paediatric patients. Kathmandu Univ Med J (KUMJ);10(39):25-9.

Sukhminder Jit Singh Bajwa, Sukhwinder Kaur Bajwa, Jasbir Kaur,et al, 2011: Dexmedetomidine and clonidine in epidural anaesthesia: A comparative evaluation. Ind J Anaesth.; 55(2):116-121. 


\section{تقييم مدى الأمان و الفاعلية للتخدير النصفى للبيوبيفاكين / ديكسميديتوميدين مقارنة بالبيوبيفاكين / فنتانيل فى الإي إصلاح الفتق الإربى الأحادى بالأطقال.}

ريم سليم، ماجستير، أيمن البغدادي، دكتور اه، لمياء الوكيل، دكتور اة وعبد العزيز عبداله ، دكتوراة

قسم الصبيلة الإكلينيكية، كلية الصيدلة ، جامعة عين شمس، القاهرة، مصر.

قسم جر احة الأطفال، كلية الطب ، جامعة عين شمس ، القاهرة، مصر.

قسم التخدير، كلية الطب، جامعة عين شمس، القاهرة، مصر.

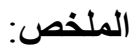

الخلفية و الهدف: المسكنات الفعالة بعد العملية الجر احية هامة من وجهة نظر المريض، ويمكُّن أيضـا من

تحسين النتائج السريرية. هدفت هذه الدراسة إلى مقارنة تأثير التخدير النصفي بوبيفكين بالإضافة إلى الفنتانيل مقابل

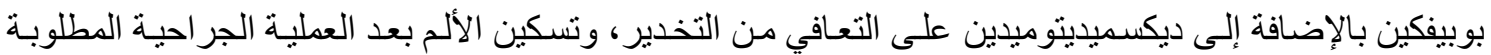

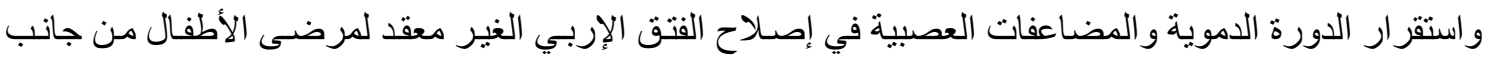

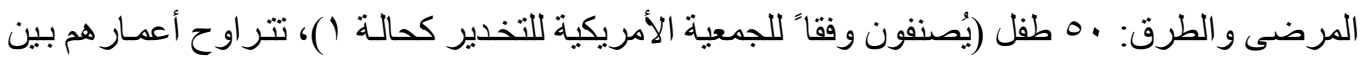

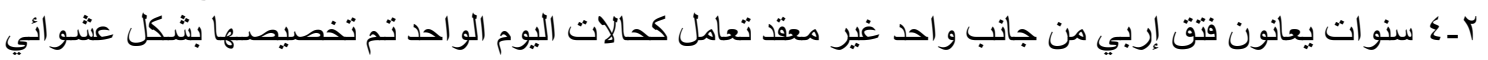

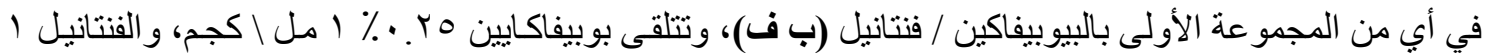

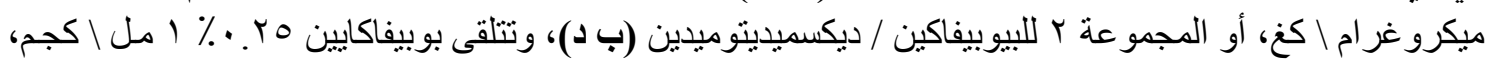
و 1 ميكرو غر ام لكغ ديكسميديتو ميدين.

وجرى تقييم المرضسى من حيث الألم و التخدير باستخدام مقيساس فـلاكك وتحديد مدى التخدير باستخدام

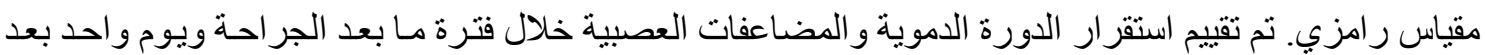

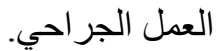

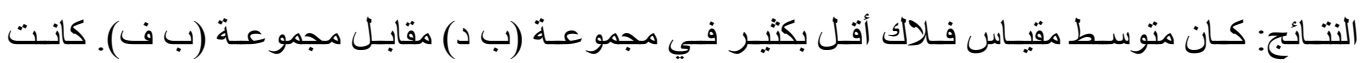

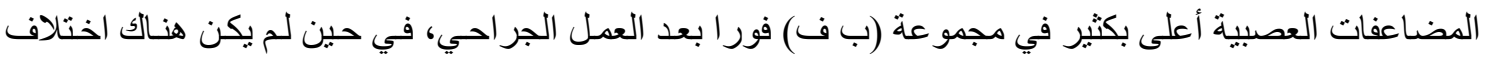

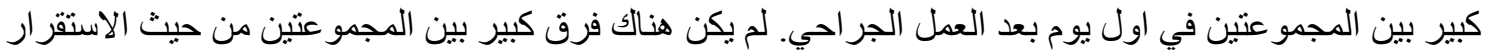

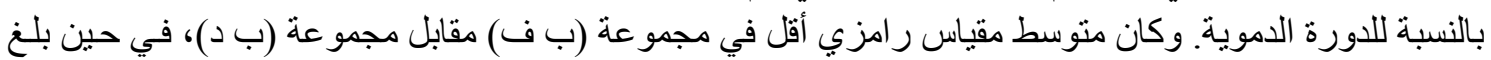

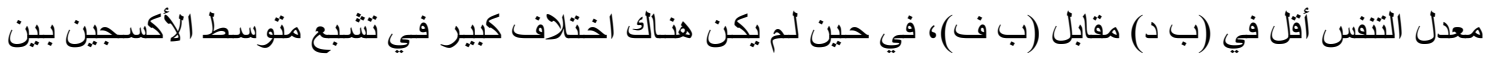

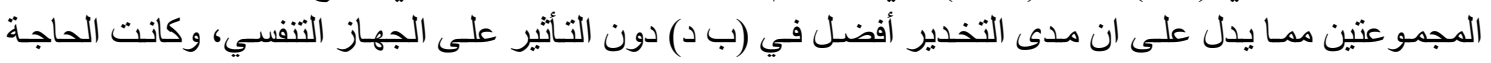
لللمسكنات لا تختلف كثير ا بين المجمو عتين.

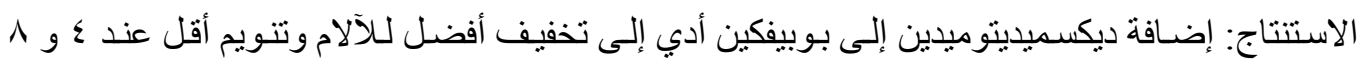

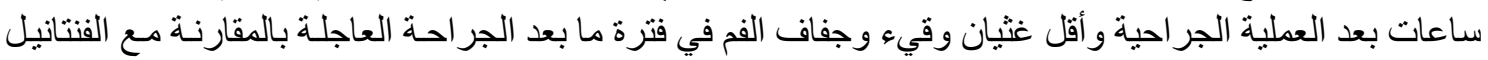
في إصلاح الفتق الإربي الغير معقد لمرضى الأطفال من جانب واحد. 